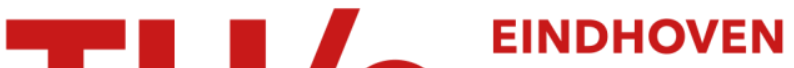

\section{Modeling loss aversion and biased self-attribution using a fuzzy aggregation operator}

\section{Citation for published version (APA):}

Lovric, M., Kaymak, U., \& Spronk, J. (2010). Modeling loss aversion and biased self-attribution using a fuzzy aggregation operator. In 2010 IEEE International Conference on Fuzzy Systems (FUZZ), 18-23 July 2010, Barcelona, Spain (pp. 1-8). Institute of Electrical and Electronics Engineers. https://doi.org/10.1109/FUZZY.2010.5584899

DOI:

10.1109/FUZZY.2010.5584899

Document status and date:

Published: 01/01/2010

\section{Document Version:}

Publisher's PDF, also known as Version of Record (includes final page, issue and volume numbers)

\section{Please check the document version of this publication:}

- A submitted manuscript is the version of the article upon submission and before peer-review. There can be important differences between the submitted version and the official published version of record. People interested in the research are advised to contact the author for the final version of the publication, or visit the $\mathrm{DOI}$ to the publisher's website.

- The final author version and the galley proof are versions of the publication after peer review.

- The final published version features the final layout of the paper including the volume, issue and page numbers.

Link to publication

\section{General rights}

Copyright and moral rights for the publications made accessible in the public portal are retained by the authors and/or other copyright owners and it is a condition of accessing publications that users recognise and abide by the legal requirements associated with these rights.

- Users may download and print one copy of any publication from the public portal for the purpose of private study or research.

- You may not further distribute the material or use it for any profit-making activity or commercial gain

- You may freely distribute the URL identifying the publication in the public portal.

If the publication is distributed under the terms of Article 25fa of the Dutch Copyright Act, indicated by the "Taverne" license above, please follow below link for the End User Agreement:

www.tue.nl/taverne

Take down policy

If you believe that this document breaches copyright please contact us at:

openaccess@tue.nl

providing details and we will investigate your claim. 


\title{
Modeling Loss Aversion and Biased Self-Attribution Using a Fuzzy Aggregation Operator
}

\author{
Milan Lovric, Student Member, IEEE and Uzay Kaymak, Member, IEEE and Jaap Spronk
}

\begin{abstract}
In this paper we use an agent-based stock market to study how investor performance and market predictions influence investor sentiment and confidence. Investor sentiment is modeled using a generalized average operator, which has been proposed in the fuzzy literature as an index of optimism. Our simulations show the impact of loss aversion on investor optimism, and the emergence of investor overconfidence through biased self-attribution. Computational models of financial markets show potential for studying the dynamics of investor psychology with respect to various market feedbacks, while the fuzzy aggregation operator used provides a convenient way of modeling those psychological effects.
\end{abstract}

\section{INTRODUCTION}

\section{A. Background}

Over the past decades, psychologists have documented many robust and systematic violations of normative theories of decision making, such as Expected utility theory, Bayesian learning, and Rational expectations [8]. Herbert Simon has emphasized bounded rationality of humans, i.e. their limited ability to adapt optimally or even satisfactorily to complex environments [25]. The idea of individual investors who are prone to judgmental biases, who are frame-dependent and use various heuristics, which might lead to anomalies on the market level, has been explored within the field of behavioral finance. Behavioral finance is the branch of finance which applies knowledge and methods from psychology and sociology to discover and explain phenomena inconsistent with the paradigm of the expected utility of wealth and narrowly defined rational behavior [10]. A number of surveys and books on behavioral finance and behavioral economics topics can be found, for example [24], [11], and [2].

A relatively novel approach for studying the link between individual investor behavior and financial market dynamics, based on agent-based methodology, has become known as Artificial Financial Markets. These are often computational models of financial markets, and are usually comprised of a number of heterogeneous and boundedly rational agents, which interact through some trading mechanism, while possibly learning and evolving. These models are built for the purpose of studying agents' behavior, price discovery mechanisms, the influence of market microstructure or the

Milan Lovric and Uzay Kaymak are with the Department of Econometrics, Erasmus School of Economics, Erasmus University Rotterdam, Burgemeester Oudlaan 50, 3062PA Rotterdam, The Netherlands (phone: +31-10-4081342; email: \{lovric,kaymak\}@ese.eur.nl). Uzay Kaymak is also with Eindhoven University of Technology, The Netherlands.

Jaap Spronk is with the Department of Finance, Rotterdam School of Management, Erasmus University Rotterdam, Burgemeester Oudlaan 50, 3062PA Rotterdam, The Netherlands (phone: +31-10-4082011; email: jspronk@rsm.nl). reproduction of the stylized facts of real-world financial time-series (e.g. fat tails of return distributions and volatility clustering). A similar bottom-up approach is used in agentbased computational economics (ACE) [27], as well as the Microscopic Simulation of econophysicists[18]. A number of reviews of studies with artificial financial markets are available, e.g. [17] and [13].

It has been recognized in the literature (e.g. [17], [5]) that agent-based financial markets are suitable for studying the topics of behavioral finance. This is because such models can easily accommodate complex learning behavior, asymmetric information, heterogeneous preferences, and ad hoc heuristics [4]. Furthermore, they can provide a link between the micro level of investor behavior and the macro level of market prices, and as such allow us to assess the relevance and market-wise implications of investor psychology. Some of the early studies that explicitly account for behavioral theories in agent-based financial market simulations are [26] and [12]. In [26] the focus is on overconfidence and loss aversion, while [12] study the social interaction between investors. In [20], [19], [21] we have studied investor overconfidence and investor sentiment in an agent-based financial market based on the Levy, Levy, Solomon (LLS) model [18].

\section{B. Sentiment and Loss Aversion}

One of the key characteristics that govern investor behavior is the optimism or pessimism of the investors. The link between asset valuation and investor sentiment has been the subject of considerable debate in the finance, and has been studied in the context of mispricing (departures from the fundamentals) [3], the limits of arbitrage [7], as well as the underreaction and overreaction of stock prices [1]. Two methodological approaches can be found in the finance literature. One is concerned with finding adequate proxies for the aggregate investor sentiment, and using them in statistical analysis to explain the variation of stock prices and the occurrences of mispricing, such as bubbles and crashes. The other one is a bottom-up approach that aims at modeling individual investor optimism and pessimism by using the insights from psychological theories. For these theories, it is important to have a flexible framework that can be adapted to capture the complexity of human decision making behavior.

In probabilistic decision theory, such as the Prospect Theory [15], [28] and Rank-Dependent Utility Theory [23], optimism and pessimism are modeled using the probability weighting function. To model optimism we would need to specify and parameterize such a probability weighting function that gives more decision weight to good outcomes 
and less decision weight to bad outcomes. However, an empirically observed probability weighting function is usually S-shaped, which means that when dealing with risky prospects, people are at the same time optimistic about the best outcomes, pessimistic about the worst outcomes, and insensitive to middle outcomes [30].

A decision maker's optimism or pessimism has also been studied within a fuzzy decision making setting. Various fuzzy connectives studied in this context have parameters that denote explicitly the optimism or pessimism degree of a decision maker. Apart from the well-known Hurwicz operator [14], the grade of compensation in ZimmermannZysno operator [31] can also be interpreted as an index of optimism. All these operators view the decision as a mixture of conjunctive and disjunctive behavior, and the degree of optimism determines which aggregation type dominates and to which degree. Another optimism-pessimism index was proposed in [29], where the parameter of the generalized averaging operator [9] is interpreted as the decision maker's characteristic degree of optimism. In this approach optimism is modeled as the disposition of the decision maker towards positive events compared to his/her disposition to consider negative events [16]. In [19] we have proposed a model of investor optimism based on the generalized averaging operator. The advantage of the proposed approach is that the influence of different levels of optimism can be studied by varying a single parameter.

In this paper we propose an updating mechanism for investor sentiment, which depends on the market performance. Investors who increase their wealth subsequently increase their optimism, while those who lose their wealth decrease their optimism (i.e. increase their pessimism). However, loss aversion as a robust finding of human psychology and decision making, suggests that people can react differently towards loses and gains ("Losses loom larger than gains." [15]). In our model we are able to incorporate this asymmetry and study its impact on the dynamics of investor sentiment. Loss aversion in our model operates through a different mechanism than in the Prospect Theory, where it is incorporated in the shape of the value function.

\section{Overconfidence and Self-attribution Bias}

Overconfidence as a judgmental bias has received a lot of attention in financial studies, and has been proposed as one of the sources of poor investor performance: some investors trade too much, which might be a manifestation of their overconfidence [22]. A type of overconfidence that has been prevalently considered in theoretical studies is the miscalibration, which means overestimating the precision of own information, e.g. by setting too narrow confidence intervals in the assessment of the value of a financial asset. One of the first papers to explicitly study behavioral issues in an agent-based model of the financial market [26], also models overconfidence as miscalibration, more specifically as underestimated variance of stock returns. The risk of a stock estimated by an overconfident investor is calculated from the historical volatility and an adjustment factor which determines the degree of overconfidence. We have used the same approach in our previous work [20], [21], where we studied investor overconfidence in the Levy, Levy, Solomon (LLS) artificial stock market [18].

For successful investors their overconfidence can be reinforced through self-attribution bias, i.e. a belief that their trading success should be attributed mostly to their own abilities [22]. In [20] we have also studied emerging overconfidence due to self-attribution bias. That study demonstrates the advantages of agent-based approach, because we can easily model the dynamics of investor attitudes based on some feedback from the market. In this paper we propose a somewhat different update mechanism using a transformation function.

\section{MODEL DESCRIPTION}

The proposed model of investor sentiment and overconfidence is based on the LLS microscopic simulation model [18] with a small homogeneous subpopulation of efficient market believers (EMBs) as described in [18], and is an extension of our previous work [21]. LLS model is a wellknown and early econophysics model, rooted in a utility maximization framework. Variants of the model have been published in a number of articles and a book, and the model has also been critically evaluated in [32].

\section{A. Asset Classes}

In the LLS model investors can choose between two investments alternatives: a risky stock (or market index) and a risk-free asset (bond). At the beginning of each period the risky asset pays a dividend which follows a multiplicative random walk according to

$$
\tilde{D}_{t+1}=D_{t}(1+\tilde{z}),
$$

where $\tilde{z}$ is a random variable distributed uniformly in the interval $\left[z_{1}, z_{2}\right]$. The bond pays interest with a rate of $r_{f}$. The simplification of only two investment alternatives is usual for agent-based markets, where multi-asset portfolio selection is typically not addressed.

\section{B. Agent Behavior}

LLS model consists of two types of investors: (1) Rational Informed Investors (RII) and (2) Efficient Market Believers (EMB). Both of these investor groups are expected utility maximizers, and the model uses power (myopic) utility function

$$
U(W)=\frac{W^{1-\alpha}}{1-\alpha}
$$

where $W$ is wealth and $\alpha$ is the risk aversion parameter.

1) RII investors: RII investors are informed about the dividend process, and therefore they can estimate fundamental value as the discounted stream of future dividend, according to the Gordon model

$$
\tilde{P}_{t+1}^{f}=\frac{D_{t}(1+\tilde{z})(1+g)}{k-g},
$$


where $k$ is the discount factor of the expected rate of return demanded by the market for the stock, and $g$ is the expected growth rate of the dividend. RII investors assume that the price will converge to the fundamental value in the next period. In period $t$ RII investor $i$ chooses the proportion $x$ of wealth to invest in stocks (the rest being invested in bonds) so that he or she maximizes the expected utility of next period wealth (the equation of which is given in [20] and also derived in [18]). Since all RII investors are assumed to have the same degree or risk aversion (parameter $\alpha$ ), they will all have the same optimal proportion $x$. As in the experiments of [18], we also assume that all investors start with the same initial wealth.

2) EMB investors: $E M B$ investors believe that the price accurately reflects the fundamental value. However, since they do not know the dividend process, they use ex post distribution of stock returns to estimate the ex ante distribution. EMB investor $i$ uses a rolling window of size $m^{i}$, and is in the original model [18] said to be unbiased if, in absence of additional information, he or she assigns the same probability to each of the past $m^{i}$ return observations [18]. Hence, the original, unbiased EMBs assume that returns come from a discrete uniform distribution

$$
\operatorname{Pr}^{i}\left(\tilde{R}_{t+1}=R_{t-j}\right)=\frac{1}{m^{i}}, \text { for } j=1, \ldots, m^{i} .
$$

The expected utility of next period wealth for EMB investor $i$ is given in [18] as

$$
\begin{aligned}
E U\left(\tilde{W}_{t+1}^{i}\right) & =\frac{\left(W_{h}^{i}\right)^{1-\alpha}}{(1-\alpha)} \sum_{j=1}^{m^{i}} \operatorname{Pr}^{i}\left(\tilde{R}_{t+1}=R_{t-j}\right) \\
& \times\left[(1-x)\left(1+r_{f}\right)+x R_{t-j}\right]^{(1-\alpha)} .
\end{aligned}
$$

$W_{h}^{i}$ represents hypothetical wealth of investor $i$ in period $t$, under the assumption that the risky asset in period $t$ has a hypothetical price $P_{h}$. This wealth is calculated from the previous period wealth, interest and dividend accumulated from the last period, and capital gains or losses incurred on the difference between the hypothetical price $P_{h}$ and the previous period price $P_{t-1}$.

In accordance with the LLS model [18], for all EMB investors an investor specific noise is added to the optimal investment proportion $x^{*}$ (that maximizes the expected utility) in order to account for various departures from rational optimal behavior $\left(\tilde{\varepsilon}^{i}\right.$ is truncated so that $0 \leq x^{i} \leq 1$, imposing the constraint of no borrowing and no shortselling), i.e.

$$
x^{i}=x^{* i}+\tilde{\varepsilon}^{i} .
$$

In [21] we have proposed general EMB type, which combines investor confidence and optimism to determine the discrete distribution of expected returns. Sentiment of investors determines the mean of that distribution, while confidence determines the peakedness of the distribution.
The prediction of the next period mean return $\tilde{\mu}_{t+1}$ is calculated as follows.

$$
\tilde{\mu}_{t+1}=\left(\frac{1}{m^{i}} \sum_{j=1}^{m^{i}}\left(R_{t-j}\right)^{s}\right)^{1 / s} .
$$

Based on the level of optimism (or pessimism), a general EMB investor $i$ centers his or her prediction of the next period return around a value which can range from the minimum to the maximum value in the rolling window $R_{t-1}, \ldots, R_{t-m^{i}}{ }^{1}$. This is achieved by using the generalized aggregation operator, which for higher values of the parameter $s$ gives higher estimate of the return (closer to the maximum value of the sample), and for lower values of the parameter $s$ gives lower estimate of the return (closer to the minimum value of the sample). In such a way, the parameter $s \in\langle-\infty, \infty\rangle$ captures the phenomena of investor optimism $s>1$ and investors pessimism $s<1$, and we call it a sentiment index. The following values of the parameter $s$ represent well-known special cases of the generalized mean, which have been studied in [19]: $s \rightarrow-\infty$ (the minimum of the sample); $s=-1$ (the harmonic mean); $s \rightarrow 0$, (the geometric mean); $s=1$ (the arithmetic mean); $s=2$ (the quadratic mean); $s \rightarrow \infty$ (the maximum of the sample). For a given sample of past returns, the relationship between the next period mean return and different values of $s$ has a sigmoid shape with horizontal asymptotes on the minimum and the maximum return in the sample. However, values close to those limits are already achieved for finite and relatively small values of positive and negative $s$.

The predicted deviation of the next period return $\tilde{\sigma}_{t+1}$ is calculated from the standard deviation $\hat{\sigma}$ of the sample of past returns $R_{t-1}, \ldots, R_{t-m^{i}}$ and the level of confidence $c$ :

$$
\tilde{\sigma}_{t+1}=c \cdot \hat{\sigma} \text {. }
$$

In this general model, we use the confidence coefficient $c \in[0, \infty\rangle$ which captures both the case of investor overconfidence $(c \in[0,1\rangle)$ and investor underconfidence $(c>1)$. Overconfident EMBs are too confident about their predictions; they underestimate the standard deviation of the distribution, making it more peaked around the generalized mean of the sample. Underconfident EMBs are less certain about future returns; they overestimate the standard deviation of returns making the distribution broader around the generalized mean.

Figure 1 shows an example of obtained probability mass functions for a specific sample of observed returns. The case of a uniform distribution represents the original, unbiased EMBs from the LLS model. For confidence coefficient $c=1$ EMB investors use the standard deviation of past returns from the rolling window. As the overconfidence increases (confidence coefficient decreases bellow 1) observed returns that are closer (further) to the mean are given a higher (lower) probability, so the distribution becomes more peaked. The

\footnotetext{
${ }^{1}$ Value $R_{t}$ is not included in the calculation because return in period $t$ is yet to be determined based on this prediction of the next period return.
} 
special case of $c=0$ is the full overconfidence where all the probability mass is given to the sample mean, so only one value represents the expected returns. Values $c>1$ represent underconfidence, as investor expectations have more spread than what past observations would suggest. In the limit case of extreme underconfidence, the distribution becomes uniform, as in the case of the original LLS model.

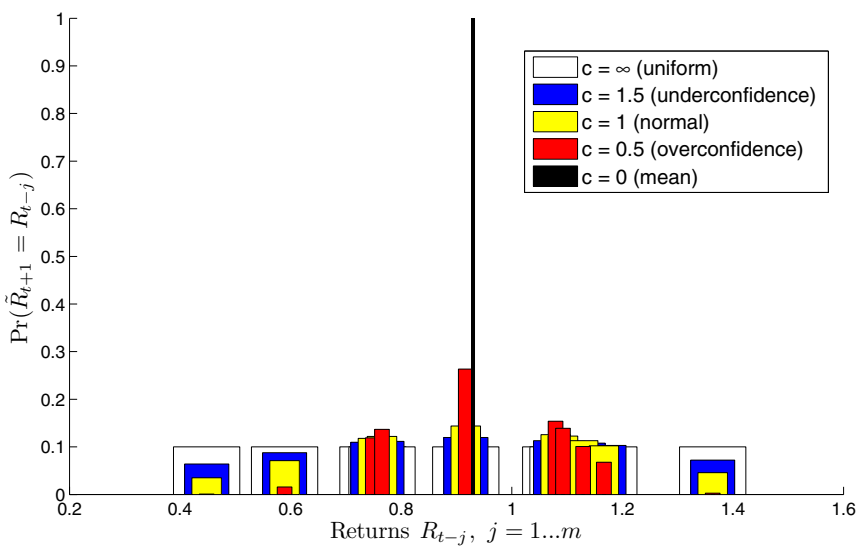

Fig. 1. Probability mass functions of observed past returns for differen levels of confidence (the central value is the arithmetic mean of the sample).

In each period of the simulation EMB investor $i$ predicts next period return by the following discrete probability distribution that incorporates the effects of investor sentiment and confidence:

$$
\operatorname{Pr}^{i}\left(\tilde{R}_{t+1}=R_{t-j}\right)=\frac{\operatorname{pdf}\left(R_{t-j} \mid \tilde{\mu}_{t+1}, \tilde{\sigma}_{t+1}\right)}{\sum_{k=1}^{m^{i}} \operatorname{pdf}\left(R_{t-k} \mid \tilde{\mu}_{t+1}, \tilde{\sigma}_{t+1}\right)},
$$

where pdf is the probability density function of a normal distribution. Since probability mass function assigns probabilities only to the returns of the rolling window, for pronounced levels of optimism or pessimism (i.e. high offset of the generalized mean from the arithmetic mean) the resulting discrete probability distribution will be skewed.

3) Updating investor psychology: (a) In this paper we model a change in investor sentiment based on the market performance of investors. The investors look at their return on investment in the last period (the relative change in their own wealth), and based on that change they update their index of optimism: If the relative return is higher than one (their wealth has increased), they increase their optimism (increase parameter $s$ ), and if the relative return is lower than one (their wealth has decreased), they decrease their optimism (decrease parameter $s$ ). In order to make this update, the parameter $s \in<-\infty, \infty>$ first needs to be mapped into $S \in<0,1>$, for which purpose we use a logistic function $L$ (see also Figure 2):

$$
L\left(s_{t}^{i}\right)=\frac{1}{1+e^{-\left(s_{t}^{i}-1\right)}}=S_{t}^{i} .
$$

The reason why the optimism index is transformed is because we want to study the dynamics of investor sentiment and graphically represent that dynamics, so after the transformation we do not have the problem of representing infinite values. In addition, the logistic function is translated horizontally so that a neutral sentiment, i.e. the border between optimism and pessimism $(s=1)$ corresponds to the middle point of the transformed interval $(S=0.5)$.

After transformation, the index $\mathrm{S}$ is modified based on the recent performance - if the wealth has increased, the optimism of EMB investors is increased by a factor $\bar{l}$ :

$$
\text { If }\left(\frac{W_{t}^{i}}{W_{t-1}^{i}}>1\right) \text { then } S_{t+1}^{i}=S_{t}^{i} \cdot \bar{l},
$$

and if the wealth has decreased, the optimism is decreased by a factor $\underline{l}$ :

$$
\text { If }\left(\frac{W_{t}^{i}}{W_{t-1}^{i}}<1\right) \text { then } S_{t+1}^{i}=S_{t}^{i} \cdot \underline{l},
$$

where $\bar{l}>1$ and $0<\underline{l}<1$. Finally, the index $\mathrm{S}$ is mapped back into the original interval $\langle-\infty, \infty\rangle$, using an inverse logistic function:

$$
s_{t+1}^{i}=L^{-1}\left(S_{t+1}^{i}\right)=1+\ln \left(\frac{S_{t+1}^{i}}{1-S_{t+1}^{i}}\right) .
$$

We study two types of updates, a symmetric update where investors are equally sensitive to losses and gains:

$$
1-\underline{l}=\bar{l}-1, \text { e.g. } \bar{l}=1.01 \text { and } \underline{l}=0.99,
$$

and an asymmetric update in which investors are more sensitive to losses than gains:

$$
1-\underline{l}=\lambda(\bar{l}-1), \lambda>1, \text { e.g. } \lambda=2, \bar{l}=1.01 \text { and } \underline{l}=0.98 \text {. }
$$

This can be seen as a way of modeling loss aversion, since investors are more impacted by negative returns than positive returns. By increasing pessimism, loss aversion decreases the mean of expected returns. In comparison with the Prospect Theory, our mechanism may be seen as more similar to the effects of non-linear probability weighting (which influences the weights given to negative outcomes) rather than value function (which influences the utility of negative outcomes). In Prospect Theory the disutility of a loss is about twice the utility of the same gain $(\lambda=2.25)$.

(b) Here we also implement un updating mechanism for investor confidence based on the success of return predictions. Similarly to [20] and [6], we add shifts in investors' confidence as a function of the investment outcomes. Let $\hat{\mu}_{t}$ and $\hat{\sigma}_{t}$ be the generalized mean (fuzzy aggregation operator) and standard deviation of the sample $R_{t-1}, \ldots, R_{t-m^{i}}$, respectively, and $c_{t}^{i}$ the confidence of investor $i$ in period $t$. For good predictions (the outcome is within two standard deviations around the generalized mean) the overconfidence increases ( $c$ decreases), while for bad predictions the underconfidence increases ( $c$ increases). First we map the confidence coefficient from $c \in[0, \infty>$ into a more convenient interval $C \in[0,1]$, for which purpose we use the following transformation function $T$ (see also Figure 3):

$$
T\left(c_{t}^{i}\right)=1-e^{-\ln 2 \cdot c_{t}^{i 1 / 4}}=C_{t}^{i} .
$$




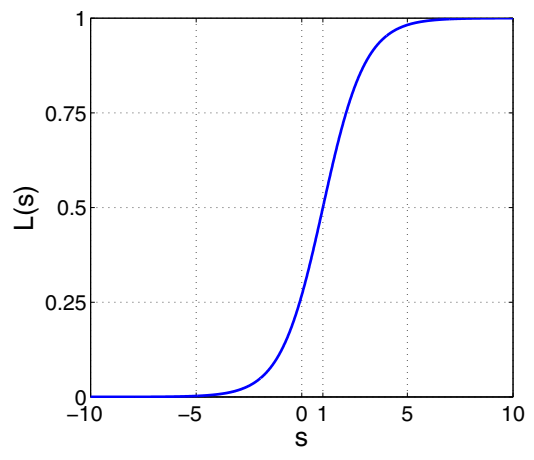

Fig. 2. Logistic function used for mapping the index of optimism. The inflection point is at $s=1$ which means that the arithmetic mean is considered as a neutral sentiment on the border between optimism and pessimism.

The updating rule is given by:

$$
\text { If } \begin{array}{r}
\left|\hat{\mu}_{t}-R_{t}\right|<2\left(c_{t}^{i} \cdot \hat{\sigma}_{t}\right) \text { then } C_{t+1}^{i}=\bar{a} \cdot C_{t}^{i}, \\
\text { Otherwise, } C_{t+1}^{i}=\underline{a} \cdot C_{t}^{i},
\end{array}
$$

where $\bar{a}>1$ and $0<\underline{a}<1$. After the update, $C$ is mapped back into the original interval $[0, \infty>$ :

$$
c_{t+1}^{i}=T^{-1}\left(C_{t+1}^{i}\right)=\left(\frac{1-C_{t+1}^{i}}{\ln 0.5}\right)^{4} .
$$

For a biased self-attribution there is an asymmetry in update: $1-\underline{a}<\bar{a}-1$ (e.g. $\bar{a}=0.75$ and $\underline{a}=1.05$ ), which means that overconfidence increases for good predictions relatively more than it decreases for bad predictions. This is because people tend to attribute success to themselves more so than they do with unsuccessful outcomes, which they rather attribute to some external effects or bad luck. We define an unbiased self-attribution as the case of a symmetric update: $1-\underline{a}=\bar{a}-1$ (e.g. $\bar{a}=0.75$ and $\underline{a}=1.25$ ).

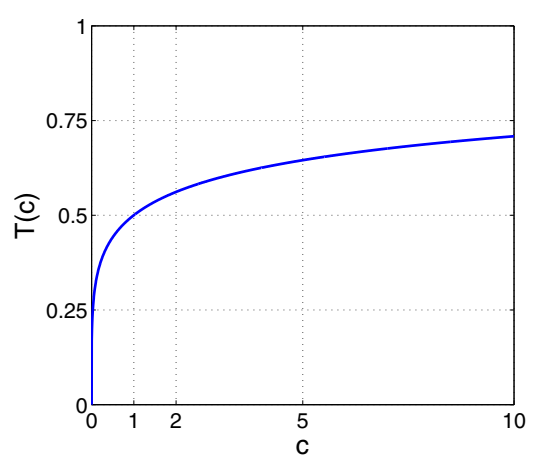

Fig. 3. Transformation function is used to map the confidence coefficient. The point $(1,0.5)$ which represents normal EMB investors $(c=0)$ is on the border between overconfident and underconfident investors.

\section{Market Mechanism}

In this paper, as in the original LLS model, the market is cleared by a temporary market equilibrium [17]. RII and EMB investors determine optimal proportion in the stock so as to maximize the expected utility of their wealth in the next period. However, expected utility is the function of the price, which is in the current period still unknown. Investors therefore need to determine optimal proportions of wealth to invest in the risky asset $x_{h}^{i}\left(P_{h}\right)$, and respective demands for shares $N_{h}^{i}\left(P_{h}\right)$, for various hypothetical prices $P_{h}$ (see Figure 4). The equilibrium price $P_{t}$ is set to that hypothetical price for which the total demand of all investors in the market equals the total number of outstanding shares, according to

$$
\sum_{i} N_{h}^{i}\left(P_{t}\right)=\sum_{i} \frac{x_{h}^{i}\left(P_{t}\right) W_{h}^{i}\left(P_{t}\right)}{P_{t}}=N .
$$

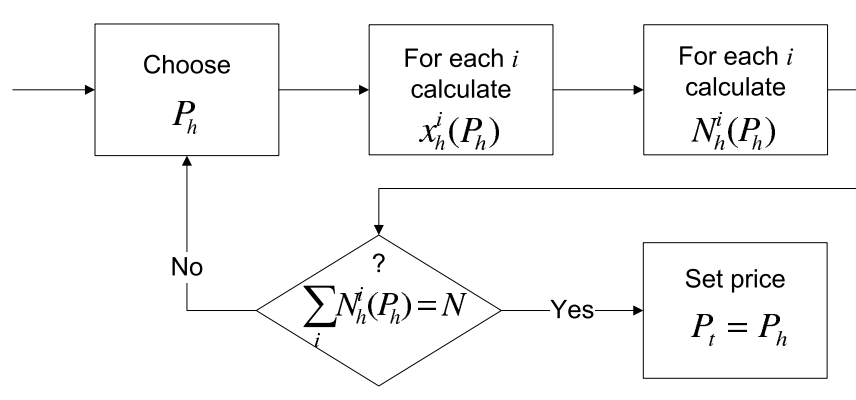

Fig. 4. Flowchart of the market mechanism (temporary market equilibrium)

\section{EXPERIMENTAL DESIGN}

TABLE I

PARAMETRIZATION

\begin{tabular}{c|c|l}
\hline \hline Symbol & Value & Explanation \\
\hline$M$ & 950 & Number of RII investors \\
$M_{2}$ & 50 & Number of EMB investors \\
$m$ & 10 & Memory length of EMB investors \\
$\alpha$ & 1.5 & Risk aversion parameter \\
$N$ & 10000 & Number of shares \\
$r_{f}$ & 0.01 & Riskless interest rate \\
$k$ & 0.04 & Required rate of return on stock \\
$z_{1}$ & -0.07 & Maximal one-period dividend decrease \\
$z_{2}$ & 0.10 & Maximal one-period dividend growth \\
$g$ & 0.015 & Average dividend growth rate \\
\hline \hline
\end{tabular}

In the benchmark model of the original study [18], where only RII investors are present in the market, there is no trade, the $\log$ prices follow random walk, and there is no excess volatility of the market price [18]. On Figure 5 it can be observed that in the benchmark model the market price closely follows the fundamental price of the risky asset.

In the experiment with a small fraction of homogeneous (with respect to memory length) and unbiased EMB investors (of the original model), the market dynamics (Figure 6) show semi-predictable booms and crashes, with substantial trading in the market and excess volatility [18]. The occurrence of these cyclic bubbles can be related to the size of the memory length of EMB investors. This experimental setup of [18] is the basis for the experiments in our paper.

In [21] we analyze market dynamics for various combinations of investor confidence and sentiment. The general 


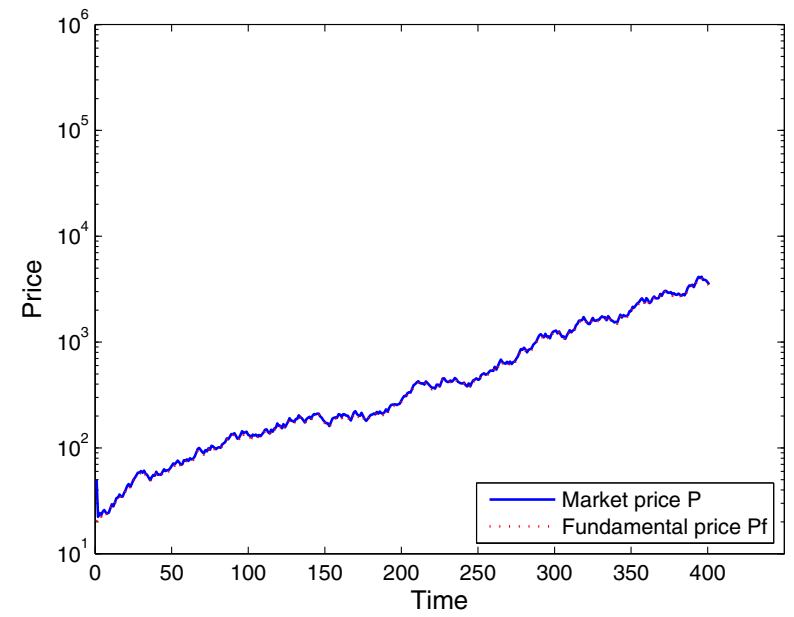

Fig. 5. Price dynamics in the benchmark model of RII.

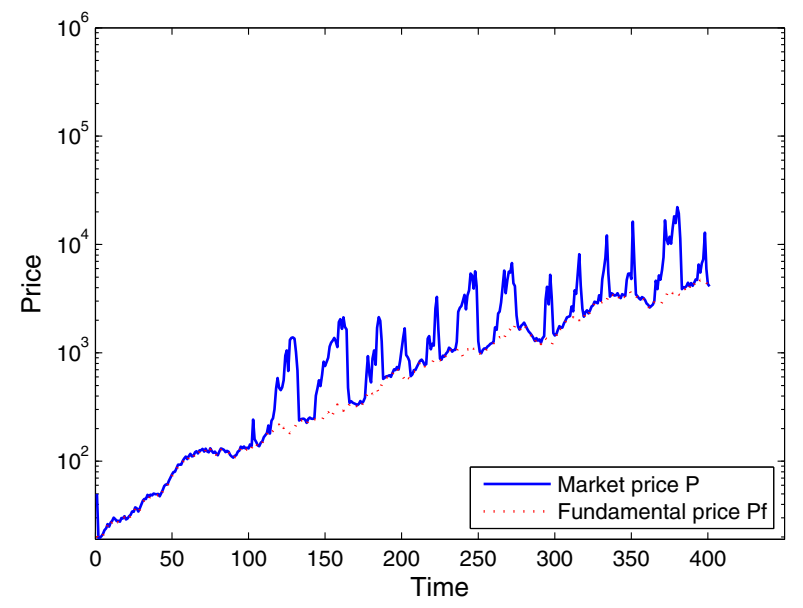

Fig. 6. Price dynamics with $95 \%$ RII and 5\% unbiased (uniform) EMB of the original LLS model.

finding is that the more optimistic EMB investors are, the higher the market bubbles (the departures of the market price above the fundamental price) are. Very pessimistic EMB investor push the market price toward the fundamental price (since they invest mostly in the risk-less asset). Overconfidence of investors augments the impact of investor sentiment, while investor underconfidence pushes the market dynamics towards the original LLS model of unbiased (uniform) EMB investors.

In this paper we study the dynamics of investor psychology (confidence and sentiment) based on the success of market predictions and market performance. Our first experiment is the difference between biased (self-attribution) and unbiased update in confidence for a fixed investor sentiment (neutral, i.e. arithmetic mean $s=1$ ). Our second experiment is the difference between biased (loss aversion) and unbiased update in sentiment for a given level of confidence (normal confidence $c=1$ ). The third experiment consist of unbiased updates, both with the confidence (unbiased self-attribution) and with the optimism (unbiased sentiment update). The fourth experiment consists of biased updates, both with the confidence (biased self-attribution) and with the optimism (loss aversion). In each experiment the market consists of 95\% RII investors and 5\% EMB investors, with the parametrization given in Table I. The observed variables are transformed confidence coefficient $T(c)$, transformed sentiment index $L(s)$, market price and fundamental price, and relative wealth of RII investors.

\section{RESUlTS}

Figure 7 shows the dynamics of confidence for biased and unbiased self-attribution, under a constant neutral sentiment (the arithmetic mean). We can observe that with unbiased update investors are slightly overconfident, but still close to the normal level that represents no miscalibration. When update is biased due to self-attribution bias, the investors become more overconfident. With a symmetric update of sentiment, investor sentiment is very optimistic throughout the simulation (Figure 8). When the update is asymmetric due to loss aversion, investor sentiment drops down slightly, but still remains very optimistic.

Figure 9 shows the dynamics of investor sentiment and confidence when both updates are unbiased. We can see that investors are very optimistic. However, their confidence varies greatly around a certain value of overconfidence close to the neutral point. The interesting finding is that even though investors are highly optimistic, which should lead to bubbles in the market price, the high volatility in confidence seems to prevent that from happening (Figure 11). Figure 10 shows the dynamics of investor sentiment and confidence when both updates are biased. Throughout the simulation, investors exhibit overconfidence, but their sentiment at a certain point shifts from mild optimism to pessimism. Market price on Figure 12 shows behavior similar to the unbiased case (Figure 11), but with some bubbles more prominent.

Finally, Figure 13 shows the dynamics of relative wealth of RII investors with respect to EMB investors when they are biased and when they are unbiased. We can see that in both cases RII investors earn more money than EMB investors, but the difference between biased and unbiased EMBs is not that prominent, with biased investors having even slight advantage. This is a rather surprising result, as we were expecting much better performance from unbiased investors due to their high levels of optimism.

\section{CONCLUSIONS}

In this paper we have studied the dynamics of investor sentiment and investor overconfidence in the modified LLS model of the stock market [21], particularly the case of a biased update in investor sentiment (due to loss aversion) and investor confidence (due to self-attribution bias). The overconfidence in the model [20] refers to the peakedness of the return distribution around the mean of return observations, while optimism in this model determines how that mean is chosen (ranging from the minimum observation to the maximum observation in the sample of past returns), which is achieved by using a fuzzy aggregation operator, namely the 


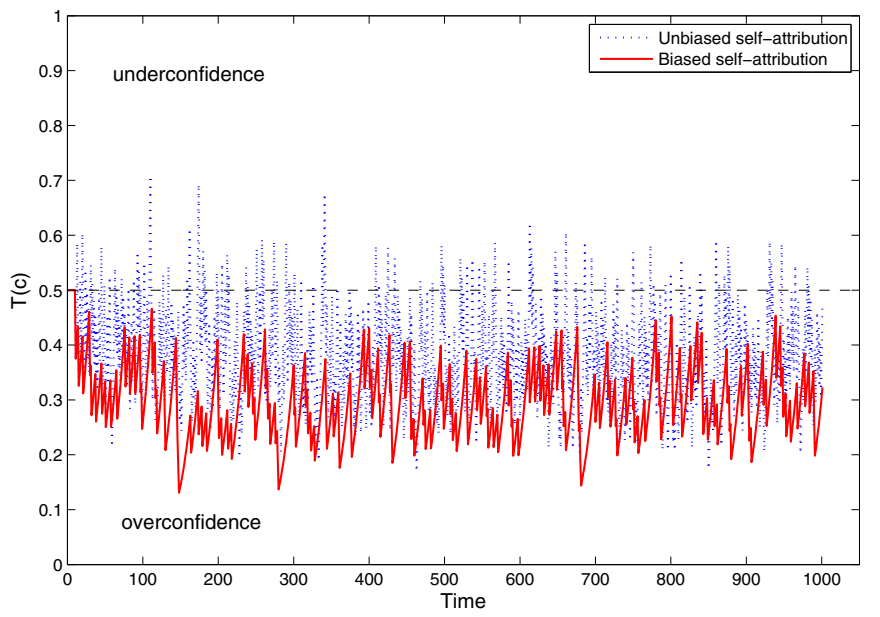

Fig. 7. The dynamics of confidence for unbiased and biased self-attribution, with a fixed neutral sentiment (arithmetic mean).

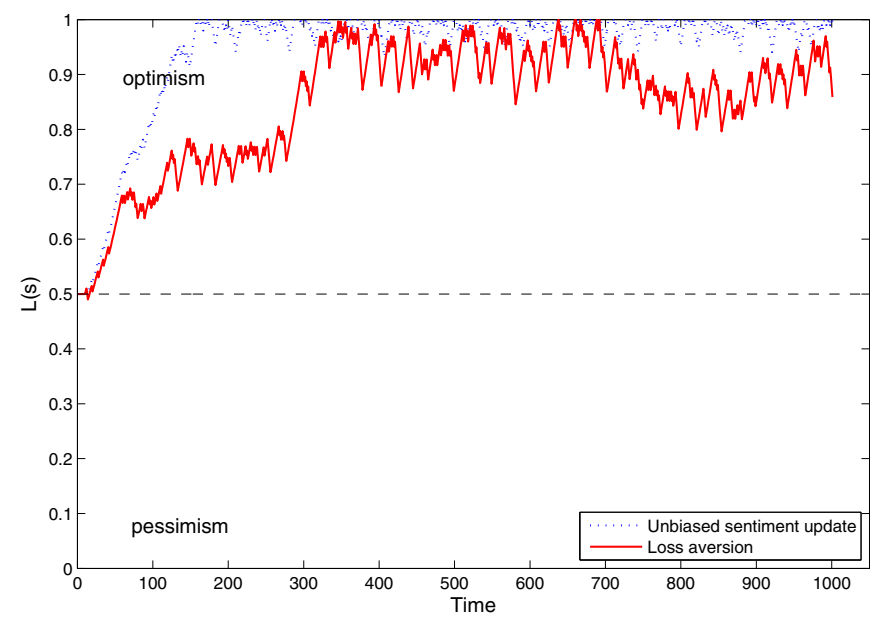

Fig. 8. The dynamics of sentiment for unbiased sentiment update and loss aversion, under a constant normal confidence level.

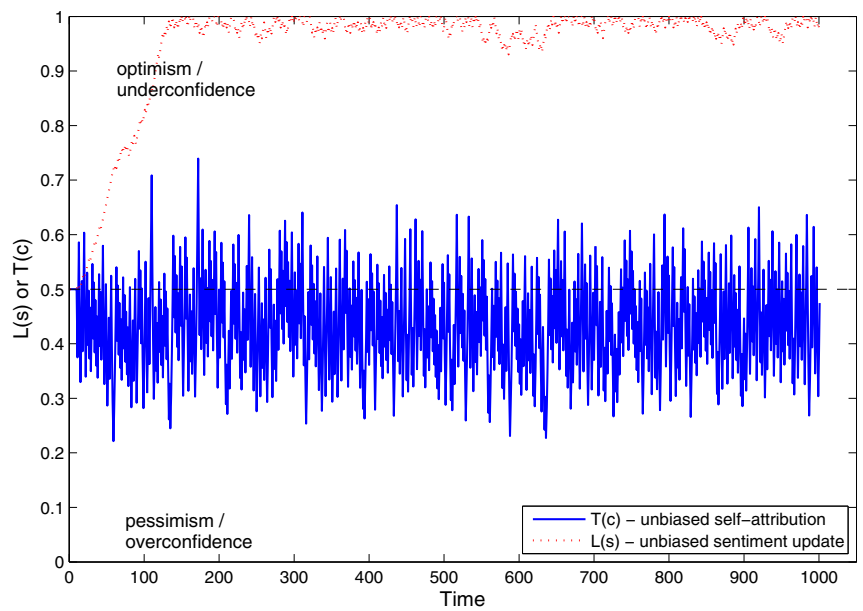

Fig. 9. The dynamics of sentiment and confidence for unbiased sentiment update and unbiased self-attribution.

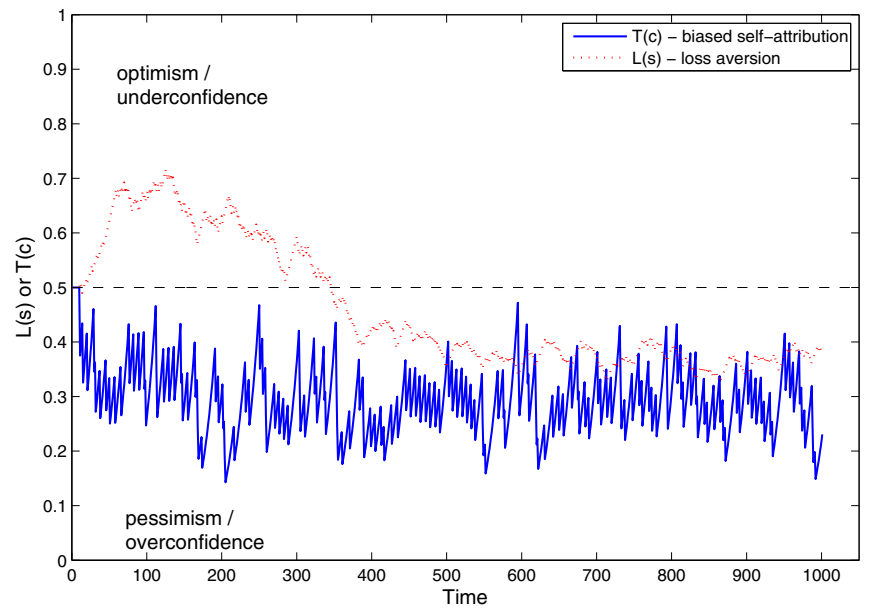

Fig. 10. The dynamics of sentiment and confidence for loss aversion and biased self-attribution.

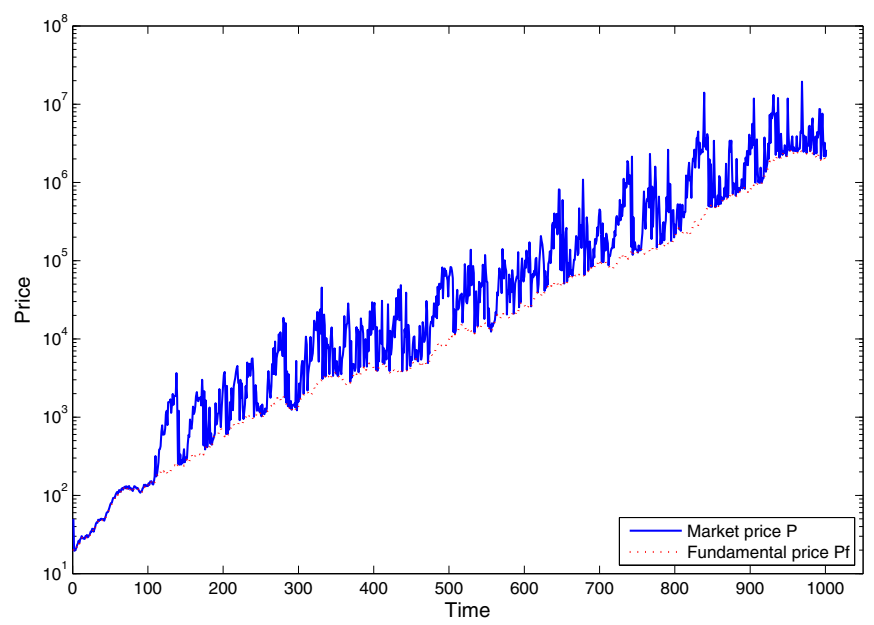

Fig. 11. Price dynamics with 95\% RII and 5\% EMB with unbiased sentiment update and unbiased self-attribution.

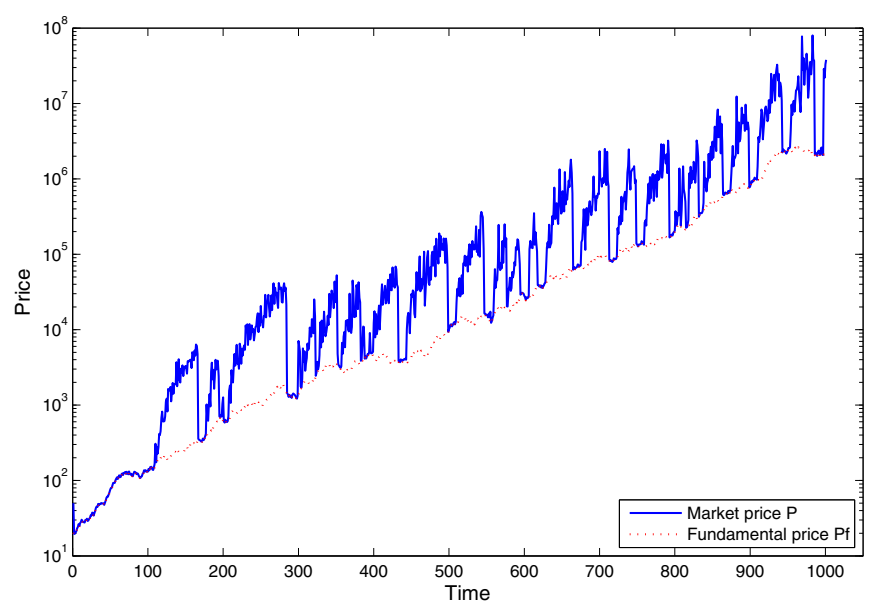

Fig. 12. Price dynamics with 95\% RII and 5\% EMB with loss aversion and biased self-attribution. 


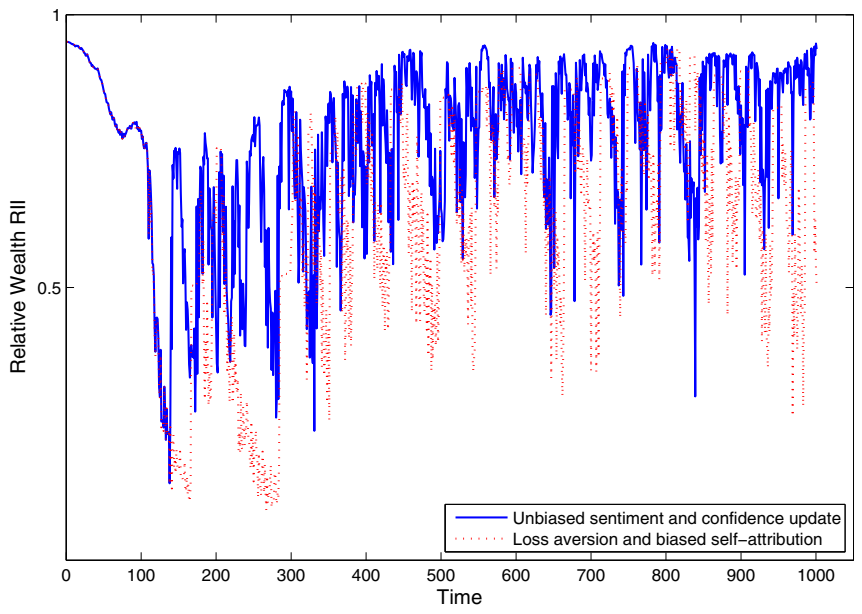

Fig. 13. Relative wealth dynamics of RII against EMBs who use biased and unbiased updates of confidence and sentiment.

generalized average. The simulations show interesting interactions between modeled psychological effects. This study also demonstrates the capabilities of computational agentbased approach for studying various behavioral phenomena.

In future extension of this work we would like to change the rules of updating mechanisms. For confidence, instead of a discrete rule which determines whether a prediction was good or bad, we would like to incorporate the magnitude of the prediction error. For optimism, we would also like to incorporate a measure of investor performance into the updating rule, instead of just checking whether the wealth has increased or decreased. An important feature of the LLS model is a positive trend, which means that strategies with higher exposure to the risky asset will be more lucrative. It would be interesting, however, to investigate the role of different market conditions, for example a declining market trend, so that we could possibly draw more general conclusions about the role of loss aversion and self-attribution bias. Furthermore, we would like to use other fuzzy aggregation operators for modeling investor decision making.

\section{REFERENCES}

[1] N. Barberis, A. Shleifer, and R. Vishny. A model of investor sentiment Journal of Financial Economics, 49(3):307-343, 1998.

[2] N. C. Barberis and R. H. Thaler. A survey of behavioral finance. In G. M. Constantinides, M. Harris, and R. M. Stulz, editors, Handbook of the Economics of Finance, volume 1, pages 1053-1128. Elsevier, 1 edition, 2003.

[3] G. W. Brown and M. T. Cliff. Investor sentiment and asset valuation. Journal of Business, 78(2):405-440, 2005.

[4] N. T. Chan, B. LeBaron, and T. Poggio. Agent-based models of financial markets: A comparison with experimental markets. MIT Artificial Markets Project, 1999.

[5] S.-H. Chen and C.-C. Liao. Behavioral finance and agent-based computational finance: toward an integrating framework. In Proceedings of 7th Joint Conference on Information Sciences, pages 1235-1238, North Carolina, USA, September 2003.

[6] K. Daniel, D. Hirshleifer, and A. Subrahmanyam. Investor psychology and security market under- and overreactions. The Journal of Finance, 53(6):1839-1885, 1998.

[7] J. B. De Long, A. Shleifer, L. H. Summers, and R. J. Waldmann. Noise trader risk in financial markets. Journal of Political Economy, 98(4):703-738, 1990
[8] W. F. DeBondt. A portrait of the individual investor. European Economic Review, 42(3-5):831-844, 1998.

[9] H. Dyckhoff and W. Pedrycz. Generalized means as model of compensative connectives. Fuzzy Sets and Systems, 14(2):143-154, 1984.

[10] G. M. Frankfurter and E. G. McGoun. Market efficiency or behavioral finance: The nature of the debate. The Journal of Psychology and Financial Markets, 1(4):200-210, 2000.

[11] J. Goldberg and R. von Nitzsch. Behavioral Finance. John Wiley and Sons Ltd, 2001.

[12] A. O. I. Hoffmann, W. Jager, and E. J. H. V. Eije. Social simulation of stock markets: Taking it to the next level. Journal of Artificial Societies and Social Simulation, 10(2), 2007.

[13] C. H. Hommes. Heterogeneous agent models in economics and finance. In L. Tesfatsion and K. L. Judd, editors, Handbook of Computational Economics, volume 2, chapter 23, pages 1109-1186. Elsevier, 1 edition, 2006.

[14] L. Hurwicz. A class of criteria for decision-making under ignorance. Cowles Commission Discussion Paper Statistics No. 356, Cowles Foundation for Research in Economics, Yale University, Feb. 1951.

[15] D. Kahneman and A. Tversky. Prospect theory: An analysis of decision under risk. Econometrica, 47(2):263-291, 1979.

[16] U. Kaymak and H. R. van Nauta Lemke. A sensitivity analysis approach to introducting weight factors into fuzzy multicriteria decision making. Fuzzy Sets and Systems, 97(2):169-182, 1998.

[17] B. LeBaron. Agent-based computational finance. In L. Tesfatsion and K. L. Judd, editors, Handbook of Computational Economics, volume 2, chapter 24, pages 1187-1233. Elsevier, 1 edition, 2006.

[18] M. Levy, H. Levy, and S. Solomon. Microscopic Simulation of Financial Markets: From Investor Behavior to Market Phenomena. Academic Press, 2000.

[19] M. Lovric, R. J. Almeida, U. Kaymak, and J. Spronk. Modeling investor optimism with fuzzy connectives. In Proceedings of the IFSA World Congress / EUSFLAT Conference, pages 1803-1808, Lisbon, Portugal, July 2009.

[20] M. Lovric, U. Kaymak, and J. Spronk. Overconfident investors in the LLS agent-based artificial financial market. In Proceedings of the IEEE Symposium on Computational Intelligence for Financial Engineering (CIFEr), pages 58-65, Nashville, USA, March-April 2009.

[21] M. Lovric, U. Kaymak, and J. Spronk. Modeling investor sentiment and overconfidence in an agent-based stock market. Human Systems Management FORTHCOMING, 2010.

[22] T. Odean. Do investors trade too much? The American Economic Review, 89(5):1279-1298, 1999.

[23] J. Quiggin. A theory of anticipated utility. Journal of Economic Behavior and Organization, 3(4):323-343, 1982.

[24] H. Shefrin. Beyond Greed and Fear - Understanding Behavioral Finance and the Psychology of Investing. Harvard Business School Press, 2000.

[25] H. A. Simon. Bounded rationality and organizational learning. Organization Science, 2(1):125-134, 1991.

[26] H. Takahashi and T. Terano. Agent-based approach to investor's behavior and asset price fluctuation in financial markets. Journal of Artificial Societies and Social Simulation, 6(3), 2003.

[27] L. Tesfatsion. Agent-based computational economics: A constructive approach to economic theory. In L. Tesfatsion and K. L. Judd, editors, Handbook of Computational Economics, volume 2, chapter 16, pages 831-880. Elsevier, 1 edition, 2006.

[28] A. Tversky and D. Kahneman. Advances in prospect theory: Cumulative representation of uncertainty. Journal of Risk and Uncertainty, 5(4):297-323, 1992.

[29] H. R. van Nauta Lemke, J. G. Dijkman, H. van Haeringen, and M. Pleeging. A characteristic optimism factor in fuzzy decisionmaking. In Proceedings IFAC Symposium on Fuzzy Information, Knowledge Representation and Decision Analysis, pages 283-288, Marseille, France, July 1983.

[30] H. U. Weber. From subjective probabilities to decision weights: The effect of asymmetric loss functions on the evaluation of uncertain outcomes and events. Psychological Bulletin, 115(2):228-242, 1994.

[31] H.-J. Zimmermann and P. Zysno. Latent connectives in human decision making. Fuzzy Sets and Systems, 4:37-51, 1980.

[32] E. Zschischang and T. Lux. Some new results on the Levy, Levy and Solomon microscopic stock market model. Physica A, 291:563-573, 2001. 